Original Contribution

\title{
COMPARATIVE INFLUENCE OF IMMOBILIZATION MEDIUM AND MUTATION ON EPS -PRODUCTION BY L. PLANTARUM MK O2 ISOLATED FROM FERMENTED MILK
}

\author{
B. Adebayo-Tayo*, O. Agidigbi, S. Alao \\ Department of Microbiology, University of Ibadan, Ibadan, Oyo State, Nigeria
}

\begin{abstract}
PURPOSE: Comparative effect of mutation and immobilization on EPS-production L. plantarum MKO2 was investigated. METHODS: L. plantarum strain and EPS produced by wild, mutants, immobilized and unimmobilized strains was characterized. RESULTS: The EPS production by the Wild type L. plantarum MK O2 and the Mutant L. plantarum Muv 11 and Muv 12 ranged from $209.89-268.19 \mathrm{mg} / \mathrm{l}$ in which the highest value was produced by Mutant L. plantarum Muv 12. EPS production on immobilization in sodium alginate ranged from 225.00 - 263.44mg/l. Mutant L. plantarum Muv 12 had the highest while Wild type $L$. plantarum MK O2 had the least. EPS - production by un -immobilized Wild type L. plantarum MK O2 and Mutant L. plantarum Muv 11 and Muv 12 ranged from $215.00-255.00 \mathrm{mg} / \mathrm{l}$. Immobilization in sodium alginate favoured EPS-production by wild type L. plantarum MK O2 (225.00 mg/l) and Mutant $L$. plantarum Muv $12(272.00 \mathrm{mg} / \mathrm{l})$ while immobilization in agar matrix favoured EPS -production by Mutant L. plantarum Muv 11 (265.67 mg/l). FT-IR spectroscopy of the EPS showed the presence of the varying degrees of functional groups which are usually associated with polysaccharides, thus confirming the EPS. CONCLUSION: Mutation and immobilization increased EPS production by the L. plantarum strains.
\end{abstract}

Key words: EPS - production, Mutation, Immobilization, Sodium alginate, Agar matrix.

\section{INTRODUCTION}

Microbial exopolysaccharides (EPS) are a broad group of polymers secreted by microorganisms, which may be associated with the cell surface as capsular polysaccharides, or excreted into the surroundings of the cell as extracellular slime (12). Lactic acid bacteria (LAB) are a very important group of bacteria normally utilized in the food industry. They are involved in the natural fermentation of a variety of foods including milk, vegetables, beverages and meat. The activities of LAB in these foods result in the production of finished products with improved properties such as enhanced aroma and flavour, extended shelf life and improved functional properties. These properties are ensured through the production of useful metabolites such as

*Correspondence to: $B$. Adebayo-Tayo, Department of Microbiology, University of Ibadan, Ibadan, Oyo State, Nigeria, E-mail address:

bukola.tayo@gmail.com lactic acid, diacetyl, hydrogen peroxide and bacteriocins. In addition to these metabolites,some $\mathrm{LAB}$ also $\mathrm{LAB}$ redirect a small proportion of fermentable sugars in their environment towards the biosynthesis of exopolysaccharides (3). A wide variety of EPS are known to be produced by several genera of LAB, including Lactobacillus, Leuconostoc, Pediococcus and Streptococcus (4). Approximately thirty species of lactobacilli are described as EPS producers. Among them, the best known are $L$. casei, $L$. acidophilus, L.brevis, $L$. curvatus, $L$. delbrueckii, $L$. helveticus, $L$. rhamnosus, $L$ plantarum and $L$. johnsonii (5). Dextran (synthesized by certain LAB such as Leuconostoc mesenteroides) was the first microbial polysaccharide to be commercially exploited and to receive authorization for use in foods (6).

Two major groups of EPS have been identified: homopolysaccharides and heteropolysaccharides. Homopolysaccharides are made up of a 
ADEBAYO-TAYO, B., et al.

single type of monosaccharide, usually glucose or fructose which occurs as repeated units of three to eight monosaccharides. Thus, they are referred to as $\alpha$-glucans (dextrans) or fructans. Heteropolysaccharides consist of at least two different sugars out of D-glucose, D-galactose and L-rhamnose in different ratios. Some other residues such as n-glycerol-3-phosphate, Nacetyl-amino sugars, phosphate and acetyl groups may also be found in EPS produced by LAB $(7,4)$. EPS produced by LAB have been are mostly composed of repeated units of a certain number of various sugar residues or sugar derivatives (8-9) joined by $\alpha$ - and $\beta$ linkages (10). The carbohydrate composition of EPS is unique to different strains of bacteria and may vary depending on the growth conditions; however, they usually consist of similar monomer subunits, with D-galactose, D-glucose and L-rhamnose occurring almost always, though in different ratios (11-14).

LABs are currently used in the production of many fermented dairy products due to their contribution to the textural characteristics of the food product through the production of EPS. For example, several strains of Lactobacillus helveticus used for mozzarella production produce EPS and contribute to water retention in the product (12-15). EPS may act both as a texturizer by improving the rheology (viscosity and elasticity) of a product, and as physical stabilizers by binding hydration water and interacting with other milk constituents (ions and proteins) thus limiting syneresis (16). EPS also contribute to human health as prebiotics or due to antitumor, immunomodulating or cholesterol-lowering activities (4). It helps probiotics to survive the gastric acid and bile salts in the gastrointestinal tract (17). The increased viscosity of foods containing EPS is thought to increase the residence time of ingested fermented milk in the gastrointestinal tract, thereby supporting transient colonization by probiotic bacteria (18).

Random mutagenesis, a classical method of strain improvement, has been widely used in the food industry to improve microbial strains with desirable qualities $(19-20)$. Since the genome of an organism controls its potential productivity, consequently, the genome may be modified to increase the potential yield. Ultraviolet (UV) light has been shown to be lethal and mutagenic in a variety of organisms, including bacteria. Mutagenic lesions are formed in the DNA as a result of exposure of cells to
$\mathrm{UV}$ radiation. Two of the most frequent lesions are the cyclobutane pyrimidine dimers and the 64 pyrimidine-pyrimidone photoproducts formed at adjacent pyrimidines (21). Other types of DNA lesions include pyrimidine hydrates, purine photoproducts, strand brakes, and DNA cross-links. These however occur at a much lower frequency (22).

Immobilisation involves restricting the mobility of microbial cells, enzymes or other proteins inside or on the surface of a carrier such that their catalytic activity is preserved (23). Currently, different immobilization techniques have found wide applications not only in the field of biotechnology, but also in pharmaceutical, environmental, food and biosensor industries (24). It is an important means of increasing the performance of microbial cultures (25) and it has been used to carry out high cell density fermentations for both cell and metabolite production. The main advantage of immobilization is easy separation of biological material from the reaction medium containing the desired product. This significantly accelerates the production process of a variety of compounds (26). Another advantage offered by immobilization is costeffectiveness of the reaction. Immobilized cell biomass may be re-used several times without necessarily re-culturing them. Other advantages offered by immobilization cell technology are protection against shear damage, high biological stability during long-term continuous fermentation $(27-29)$ improved resistance to contamination and bacteriophage attack, enhancement of plasmid stability and prevention from washing-out during continuous cultures (30). This research aimed at investigating the comparative influence of immobilization medium on EPS - production by L. plantarum MK O2 isolated from fermented milk.

\section{MATERIALS AND METHODS}

\section{Bacterial Strains}

The Lactobacillus plantarum strain used in this study was isolated from milk obtained from Sabo market in Ibadan, Oyo State, Nigeria.

\section{Isolation of Organisms}

The milk sample was allowed to ferment in the laboratory for 48 hours after which isolation of the $\mathrm{LAB}$ was carried out according to the method of Sobrun et al (30). Serial dilution of the sample was carried out and it was plated on de Man, Rogosa and Sharpe (MRS) agar supplemented with sucrose $(2 \% \mathrm{w} / \mathrm{v})$, sodium azide $(0.02 \% \mathrm{w} / \mathrm{v})$ and bromocresol purple 
$(0.012 \% \mathrm{w} / \mathrm{v})$. The cultures were incubated at $35^{\circ} \mathrm{C}$ for 48 hours under anaerobic conditions. Mucoid and ropy colonies exhibiting yellow zones were selected and re-streaked on MRS agar repeatedly to obtain pure cultures. The isolates were maintained on MRS agar slants $4^{\circ} \mathrm{C}$ and in a maintenance medium consisting of MRS broth with $20 \%$ glycerol.

\section{Quantification of EPS produced by the strains}

The amount of EPS produced was determined according to the method of Dubois et al. (31) using the exopolysaccharide selection medium (ESM) described by Van den Berg (32) and modified by Ludbrook et al. (33). The sterile ESM was inoculated with 24 hour broth culture of the $\mathrm{LAB}$ isolates and incubated at $35^{\circ} \mathrm{C}$ for 24 hours. The cultures were heated in a water bath at $80^{\circ} \mathrm{C}$ for 15 minutes and left to cool at room temperature. They were then treated with $5 \%$ $(\mathrm{w} / \mathrm{v})$ trichloroacetic acid (TCA) and left at $4^{\circ} \mathrm{C}$ overnight followed by centrifugation at $15000 \mathrm{~g}$ for 20 minutes at $4^{\circ} \mathrm{C}$ to remove cells and precipitated proteins. The crude EPS was precipitated out by the addition of two volumes of chilled absolute ethanol and kept at $4{ }^{\circ} \mathrm{C}$ overnight. The samples were centrifuged again at $15000 \mathrm{~g}$ for 10 minutes and the resulting precipitate re-dissolved in $10 \mathrm{ml}$ of water. Phenol $(1 \mathrm{ml}, 5 \% \mathrm{w} / \mathrm{v})$ was added to $1 \mathrm{ml}$ of the dissolved precipitate in a test tube and allowed to stand for 1 minute. $5 \mathrm{ml}$ of concentrated sulphuric acid was added and allowed to stand for 30 minutes. The absorbance was measured using a spectrophotometer at $490 \mathrm{~nm}$ against a blank (distilled water) and compared to a graph generated from the results obtained for a series of D-glucose standards to determine the sugar concentration. The L. plantarum strain used in this study was selected because of its high EPS production capacity.

\section{Identification of Isolate}

Identification of the isolate was carried out using morphological, physiological and biochemical characteristics such as gram staining, casein hydrolysis, starch hydrolysis, gelatin hydrolysis, oxidase test, homofermentative and heterofermentative test and carbohydrate fermentation.

Confirmation of the identity was done using molecular characterization. DNA extraction was carried out according to the method of De et al. (34). The isolated DNA was then used as a template for selective amplification by the
ADEBAYO-TAYO, B., et al. Polymerase Chain reaction (PCR). DNA sample from the isolate obtained by this protocol were assayed by restriction enzyme digestion. Sequencing of the fragments was carried out using the automatic Big Dye (dideoxy chain terminator) sequencer ABIPRISM 3730xl. For identification of the closest relatives, newly determined sequences were compared to those available in the $\mathrm{V} 2-\mathrm{V} 3$ region of the 16S rRNA sequences using the GenBank DNA databases and the standard nucleotide-nucleotide BLAST algorithm.

\section{Molecular Identification of the Highest EPS- Producing Strains}

The highest EPS -producing L. plantarum (MK 02) was identified using molecular technique based on the 16SrRNA gene amplification by polymerase chain reaction (PCR). Purification of the PCR products and the determination of sequences were performed by Macrogen USA (9700 Great Seneca Highway, Rockville, MD 20850, USA). The amplified gene was sequence and the sequence compared with the NCBI database

(http://blast.ncbi.nlm.nih.gov/Blast.cgi).

\section{Mutagenesis}

Ultraviolet radiation was used to induce mutagenesis in the L. plantarum strain. Dilutions of the bacterial culture were plated on MRS agar and irradiated with UV light of wavelength 254 $\mathrm{nm}$ at a distance of $30 \mathrm{~cm}$ for $5,10,15,20,25$, 30, 60, 90 and 120 seconds. Cultures which were not exposed to UV radiation served as control. The cultures were wrapped in aluminium foil to prevent the penetration of light which induces photoreactivation and incubated at $35^{\circ} \mathrm{C}$ for 24 hours. Colony count of all the cultures was carried out and colonies were selected from cultures having $2 \%$ survival rate.

\section{Immobilisation of Cells}

In Sodium alginate: The entrapment method was used to immobilise the cells in sodium alginate according to the method of Pasha et al. (35). Two gram $(2 \mathrm{~g})$ of sodium alginate was dissolved in $100 \mathrm{ml} 0.9 \% \mathrm{NaCl}$. The solution was then autoclaved at $121^{\circ} \mathrm{C}$ for $15 \mathrm{~min}$ and $2 \mathrm{ml}$ inoculums of wild type whole cells and mutants each were added to $10 \mathrm{ml}$ of the solution prepared. The sodium alginate-cell solution was then added drop wise with stirring to a $0.1 \mathrm{M}$ $\mathrm{CaCl}_{2}$ solution. The gel beads formed were left in solution for 1 hour before being filtered off. The beads were then washed in a $0.9 \% \mathrm{NaCl}$ solution for $20 \mathrm{~min}$. 
ADEBAYO-TAYO, B., et al.

In Agar: The method of Manohar and Karegoudar (36) was used to immobilize both wild type and mutant cells in agar matrix. The LAB strains were cultured in MRS broth for 12 hours and centrifuged at $5000 \mathrm{rpm}$ for 10 minutes to obtain cell pellets. The cell pellets were suspended in sterile saline solution and mixed with sterile 4\% (w/v) agar-saline solution, allowed to set and cut with a sterile cork borer to obtain cell-entrapped beads. The agar beads were washed successively with distilled water and saline.

\section{Production of EPS by Un-immobilized Wild type and Mutant Strains \\ The bacterial cells were grown in MRS broth at $35^{\circ} \mathrm{C}$ for 18 hours after which the broth cultures were used to inoculate the exopolysaccharide selection medium $(10 \% \mathrm{v} / \mathrm{v})$ and incubated at $35^{\circ} \mathrm{C}$ for 48 hours. The EPS produced was then isolated and purified according to the method of Cerning et al. (37). Quantification of the EPS was carried out as described by Dubois et al. (31).}

\section{Production of EPS by Immobilised Wild type and Mutant Strains}

The exopolysaccharide selection medium was inoculated with $5 \%(\mathrm{w} / \mathrm{v})$ of the immobilised cells according to the method of Karigar et al. (38) and incubated at $35^{\circ} \mathrm{C}$ for 48 hours. The EPS produced was isolated and purified according to the method of Cerning et al. (39) while its quantification was carried out using the method described by Dubois et al. (31).

\section{Fourier Transform Infrared Spectroscopy (FT-IR) of EPS}

The EPS were prepared for infrared analysis by grinding a mixture of $2 \mathrm{mg}$ of the EPS with 200 mg dry $\mathrm{KBr}$, followed by pressing the mixture into a $16 \mathrm{~mm}$ diameter mold. The Fourier transform-infrared (FT-IR) spectra were recorded on a Shimadzu IR Affinity $1 S$ instrument with a resolution of $4 \mathrm{~cm}^{-1}$ in the $4000-400 \mathrm{~cm}^{-1}$ region.

\section{RESULTS AND DISCUSSION}

The isolate was characterized genotypically and the EPS produced by the strains was characterized. A BLAST (Basic Local Alignment Search Tool) analyses of the 16SrRNA gene nucleotide sequence of strain MKO2 amplified product showed a 97\% similarity to $L$. plantarum. A phylogenetic tree was constructed between it and similar sequences found in GenBank.

Molecular identification of the LAB strain MK 02 as Lactobacillus plantarum follows the trend of previous works which have identified this organism as a potent EPS producer. Talon et al. (40) and Francois et al. (41) reported the production of both capsular and extracellular EPS by L. plantarum strains. Remus et al. (42) reported the presence of four clusters of genes in the genome of $L$. plantarum which are associated with surface polysaccharide production, indicating the capacity of this strain for EPS production.

The wild type L. plantarum strain (MK 02) used in this study produced an EPS concentration of $218.67 \mathrm{mg} / \mathrm{l}$ after 18 hours of fermentation in a medium containing skim milk. EPS produced by wild type $L$. plantarum MK 02 is shown in Figure 1.

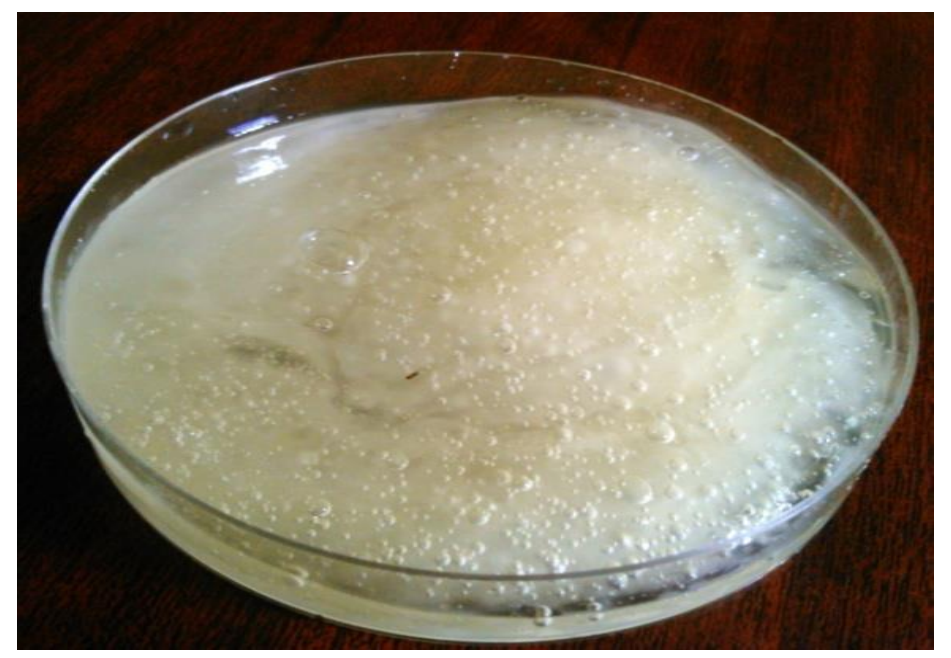

Figure 1. EPS produced by wild type $L$. plantarum MK 02 
This study was carried out with the aim of increasing the EPS production capacity of the isolate using mutagenesis and immobilization techniques.

\section{Induction of Mutation in the Parental Strain} The parental wild type strain (MK 02) was exposed to ultraviolet (UV) radiation which is a known physical mutagen. The number of colony forming units (CFU) observed after UV exposure at various time intervals ranging from 0 to 120 seconds is shown in Table 1. Exposure time zero (0) represents the control which was not exposed to UV radiation. The control
ADEBAYO-TAYO, B., et al. produced $2040 \mathrm{CFU}$ at the $10^{-4}$ dilution, which corresponds to $100 \%$ survival. The CFU reduced to $1836,1836,408,40,16$ and 10 after UV exposure for $5 \mathrm{~s}, 10 \mathrm{~s}, 20 \mathrm{~s}, 30 \mathrm{~s}, 60 \mathrm{~s}$ and $120 \mathrm{~s}$ respectively at the $10^{-4}$ dilution. At the $10^{-5}$ dilution, the total CFU decreased from 1252 in the control to $1189,62,6,25,37$ and $6 \mathrm{CFU}$ after UV irradiation for $5 \mathrm{~s}, 10 \mathrm{~s}, 20 \mathrm{~s}, 30 \mathrm{~s}, 60 \mathrm{~s}$ and 120 s respectively. The $10^{-6}$ dilution resulted in a count of $968 \mathrm{CFU}$ in the control while the count reduced to 484, 242, 96, 9, 4 and $19 \mathrm{CFU}$ after 5s, 10s, 20s, 30s, 60s and 120s of UV irradiation respectively.

Table 1. Effect of $U V$ radiation on the colony forming unit and survivability of cell

\begin{tabular}{|c|c|c|c|c|}
\hline Exposure time (s) & Dilution & CFU & Survival rate $(\%)$ & Average survival rate (\%) \\
\hline \multirow[t]{3}{*}{0} & $10^{-4}$ & 2040 & 100 & 100 \\
\hline & $10^{-5}$ & 1252 & 100 & \\
\hline & $10^{-6}$ & 968 & 100 & \\
\hline \multirow[t]{3}{*}{5} & $10^{-4}$ & 1836 & 90 & 78 \\
\hline & $10^{-5}$ & 1189 & 95 & \\
\hline & $10^{-6}$ & 484 & 50 & \\
\hline \multirow[t]{3}{*}{10} & $10^{-4}$ & 1836 & 90 & 40 \\
\hline & $10^{-5}$ & 62 & 5 & \\
\hline & $10^{-6}$ & 242 & 25 & \\
\hline \multirow[t]{3}{*}{15} & $10^{-4}$ & 40 & 20 & 9 \\
\hline & $10^{-5}$ & 62 & 5 & \\
\hline & $10^{-6}$ & 193 & 2 & \\
\hline \multirow[t]{3}{*}{20} & $10^{-4}$ & 408 & 20 & 10 \\
\hline & $10^{-5}$ & 6 & 0.5 & \\
\hline & $10^{-6}$ & 96 & 10 & \\
\hline \multirow[t]{3}{*}{25} & $10^{-4}$ & 10 & 0.5 & 4 \\
\hline & $10^{-5}$ & 12 & 1 & \\
\hline & $10^{-6}$ & 96 & 10 & \\
\hline \multirow[t]{3}{*}{30} & $10^{-4}$ & 40 & 2 & 2 \\
\hline & $10^{-5}$ & 25 & 2 & \\
\hline & $10^{-6}$ & 9 & 1 & \\
\hline \multirow[t]{3}{*}{60} & $10^{-4}$ & 16 & 0.8 & 1 \\
\hline & $10^{-5}$ & 37 & 3 & \\
\hline & $10^{-6}$ & 4 & 0.5 & \\
\hline \multirow[t]{3}{*}{90} & $10^{-4}$ & 40 & 2 & 1 \\
\hline & $10^{-5}$ & 12 & 1 & \\
\hline & $10^{-6}$ & 9 & 1 & \\
\hline \multirow[t]{3}{*}{120} & $10^{-4}$ & 10 & 0.5 & 1 \\
\hline & $10^{-5}$ & 6 & 0.5 & \\
\hline & $10^{-6}$ & 19 & 2 & \\
\hline
\end{tabular}


The survival rate after UV exposure as seen in Figure 2 shows that after 5 s of UV irradiation, $78 \%$ of the cells were found to have survived, $10 \%$ survived 20 s of UV irradiation while only

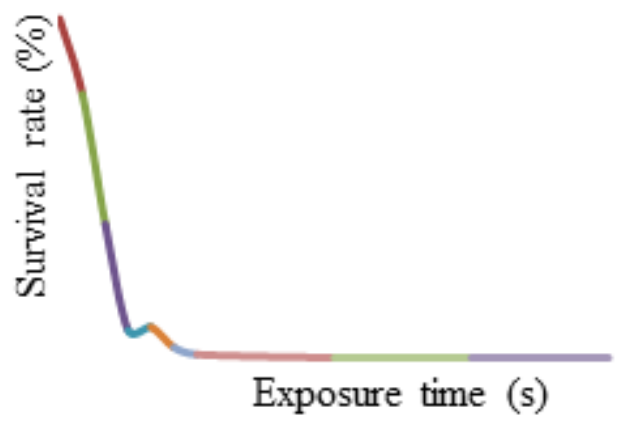

ADEBAYO-TAYO, B., et al. $1 \%$ were able to grow after 120 s of radiation. In general, the percentage of organisms which survived the UV irradiation reduced as the exposure time increased.

Figure 2. Survival rate of $L$. plantarum cells after exposure to UV radiation

Following the mutagenesis procedure, 12 mutants were selected and further screened for EPS production. The EPS production rate of the mutant strains (Muv 1- Muv 12) as compared to the wild type (MK 02) is shown in Figure 3. The wild type L. plantarum $\mathrm{MK} \mathrm{O} 2$ and the selected mutants have the ability to produce EPS. The EPS-production ranged from $98.00-$ 240.00mg/l. Four mutants (Muv7, Muv 10, Muv 11 and Muv 12 produced higher EPS than the wild type while the rest 8 mutants produced EPS lower than the wild type L. plantarum MK O2. The two highest EPS-producing mutant $L$. plantarum Muv 11 and Muv 12 were selected for further study.

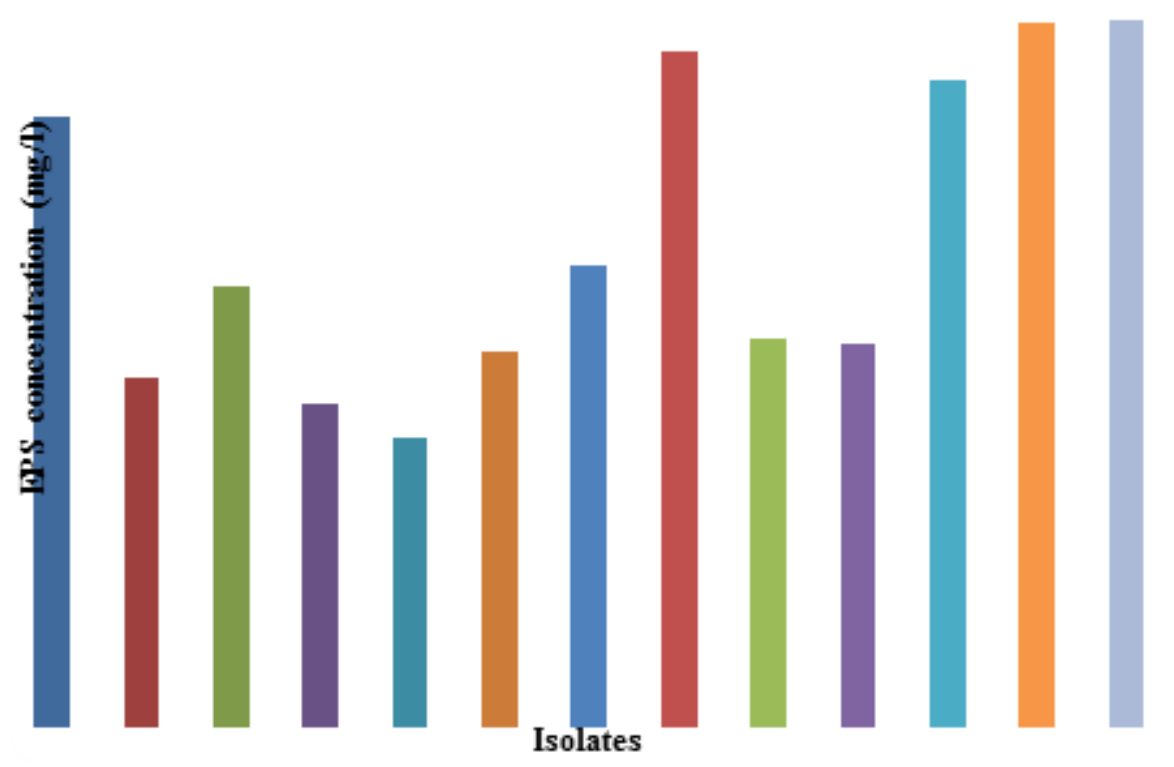

Figure 3. Comparism of EPS production by wild type $L$. plantarum MK O2 and Mutant $L$. plantarum Muv 11 and Muv 12

The results of ultraviolet mutagenesis in the $L$. plantarum strain (MK 02) indicate that the rate of survival of the organism decreased as the time of exposure to UV radiation increased. The number of cells which survived UV irradiation reduced drastically from $2.04 \times 10^{3} \mathrm{CFU}$ to about 10 CFU after 120s of UV exposure,thereby achieving a survival rate of $1 \%$ at 120 s of UV irradiation. Four, out of the twelve mutants isolated showed more yields of EPS than the wild type strain. This implies that the genetic modifications that occurred in the LAB as a result of random mutagenesis had led to the development of strains with improved characteristics. Increase in EPS production from $218.67 \mathrm{mg} / \mathrm{l}$ in the wild type strain MK 02 to $252.0 \mathrm{mg} / \mathrm{l}$ and $253.22 \mathrm{mg} / \mathrm{l}$ in its mutant strains 
Muv 11 and Muv 12 respectively represent about $14 \%$ increase in EPS production. Previous studies have shown UV radiation to be a potent mutagenic agent and it has been used as a strain improvement technique for the development of microbial strains capable of producing higher yields of desired metabolites. Increased lactic acid production was observed by Sobrun et al. (30) in a mutant strain of LAB which produced a maximum concentration of $29.0 \mathrm{~g} / \mathrm{l}$, compared to the wild type strain which produced about 19.0 $\mathrm{g} / \mathrm{l}$ of lactic acid. Pasha (43) also reported higher yields of glutamic acid from UV-induced mutants of Corynebacterium glutamicum.

\section{Cell Immobilization}

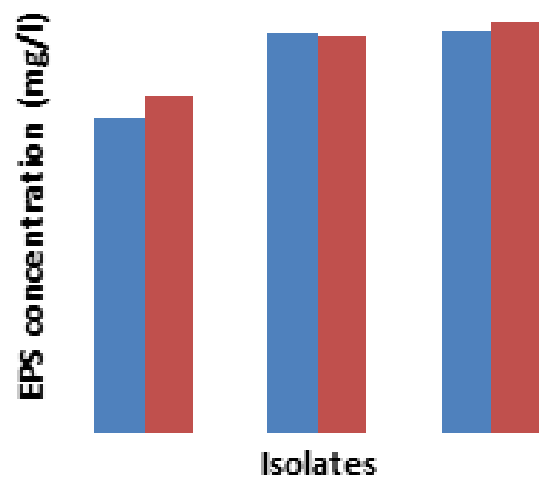

ADEBAYO-TAYO, B., et al. Immobilization of wild type $L$. plantarum MK $\mathrm{O} 2$ and the mutant L. plantarum Muv 11 and Muv 12 on agar matrix and sodium alginate is shown in Figure 4. The EPS production by the wild type $L$. plantarum MK O2 and the Mutant L. plantarum Muv 11 and Muv 12 when immobilized on agar matrix ranged from 209.89 - 268.19mg/l in which the highest value was produced by Mutant L. plantarum Muv 12 and the least was produced by wild type $L$. plantarum MK O2.

The EPS - production by wild type L. plantarum MK O2 and the Mutant L. plantarum Muv 11 and Muv 12 when immobilized on sodium alginate ranged from $225.00-263.44 \mathrm{mg} / 1$.

Figure 4. EPS production by wild type L. plantarum MK O2 and Mutant L. plantarum Muv 11 and Muv 12 immobilized in agar and sodium alginate.

Mutant L. plantarum Muv 12 had the highest value while wild type $L$. plantarum MK O2 had the least.

Increased EPS production resulted from immobilization of both wild type and mutant strains. Immobilization in sodium alginate favoured EPS-production by wild type $L$. plantarum MK O2 (225.00mg/l) and Mutant $L$. plantarum Muv $\quad 12 \quad(272.00 \mathrm{mg} / \mathrm{l})$.
Immobilization in agar matrix favoured EPS production by Mutant L. plantarum Muv 11 (265.67mg/l).

Figure 5 shows EPS production by the unimmobilized cells. EPS - production by un immobilized wild type L. plantarum MK O2 and mutant L. plantarum Muv 11 and Muv 12 ranged from $215.00-255.00 \mathrm{mg} / \mathrm{l}$. Mutant $L$. plantarum Muv 12 had the least production.
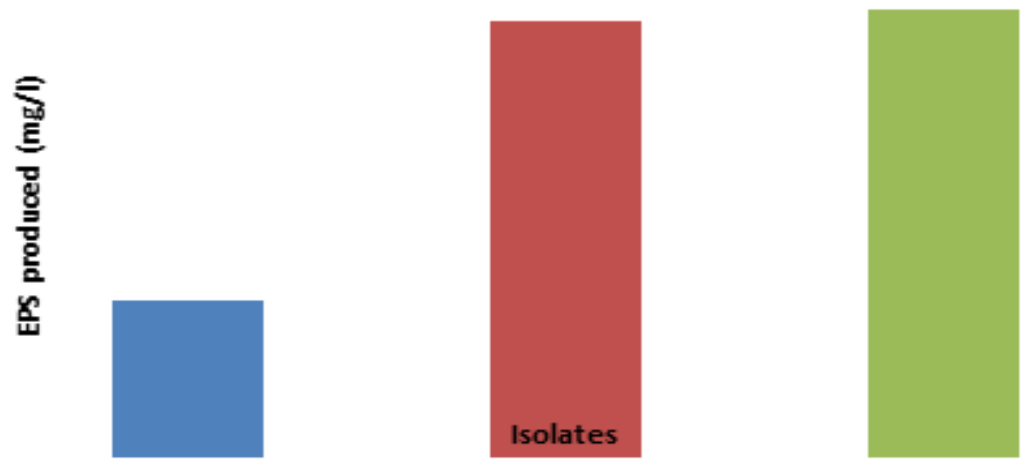

Figure 5. EPS production by un-immobilized wild type L. plantarum MK O2 and Mutant L. plantarum Muv 11 and Muv 12 
Immobilization of wild type and mutant strains of LAB was carried out to improve the EPS production capacity of the strains. Immobilized cell technology has been applied in a wide variety of research applications. For instance, the high potential of Lactobacillus rhamnosus RW-9595M for EPS production and the importance of immobilized cell technology were emphasized in the studies of Bergmaier et al. (44) and Bergmaier et al. (45).

From this study, higher EPS concentrations were obtained from immobilized cells as compared to un-immobilized cells, while sodium alginate was a more favourable matrix for immobilizing cells for enhanced EPS production. From these investigations, immobilization in sodium alginate produced up to $7 \%$ increase in EPS production in the mutant Muv 12 while agar immobilization produced about 5\% increase in EPS yield as observed in Muv 11. The increase in EPS production by immobilized cells could be attributed to the fact that immobilization enables the concentration of high density of cells in the immobilization matrix, thus making more cells available for EPS production. Competition between cells may be reduced when immobilized than when they are free in the medium as fewer cells are encapsulated within each unit of the immobilization matrix. Also, prevention of feedback inhibition could account for higher yields of EPS by immobilized cells because as the EPS is being produced, the immobilization matrix separates the cells from the products formed. Thus, inhibition of further EPS synthesis is prevented. These observations are in agreement with the work of El-Gizawy et al. (46) where the production of EPS was found to have been enhanced by microencapsulation due to an increase in the viable count of the used strain of Lactobacillus bulgaricus. Ismail and
ADEBAYO-TAYO, B., et al. Nampothiri (47) also studied EPS production by encapsulated $L$. bulgaricus and found that encapsulated cells gave higher EPS production than free cells.

\section{Characterization of the EPS produced by the strains using Fourier Transform Infrared (FT-IR) Spectroscopy}

The EPS produced by the bacterial strains was analysed using FT-IR to determine the functional groups present in them. The spectra produced by the EPS of both wild type (Figure 6a) and mutant strains (Figure 6b, Figure 6c) showed similarities in having absorption peaks around $3000 \mathrm{~cm}^{-1}$ (characteristic of carbon- and hydrogen-containing species), $2928 \mathrm{~cm}^{-1}$ (corresponding to methyne $\mathrm{C}-\mathrm{H}$ stretch), $2070 \mathrm{~cm}^{-1}$ ( CO group), $1654 \mathrm{~cm}^{-1}$ (indicating the presence of olefinic un-saturation $\mathrm{C}=\mathrm{C}$ ), 1456$1236 \mathrm{~cm}^{-1}$ (representing the phenol or tertiary alcohol bend), $1153-1101 \mathrm{~cm}^{-1}$ (tertiary alcohol C-O stretch), $1051 \mathrm{~cm}^{-1}$ (C-H out-of-plane bending) and $908-455 \mathrm{~cm}^{-1}$ (alcohol $\mathrm{OH}$ out-ofplane bend). Absorptions in the region of $3300 \mathrm{~cm}^{-1}$ indicate that the compound is likely to be unsaturated or aromatic while peaks at $1654 \mathrm{~cm}^{-1}$ further highlight the presence of unsaturation in the EPS. The absorption peak at $2063.90 \mathrm{~cm}^{-1}$ shows the presence of nitrogen compounds having multiple bonds such as cyanides (nitriles), cyanates, isocyanates, thiocyanates and diazo compounds (48). Also, the presence of multiply-bonded $\mathrm{CO}$ group is indicated by absorption bands around $2000 \mathrm{~cm}^{-1}$. However, the EPS produced by both mutants differ from that of the wild type strain in having one peak less in the regions $1456.30-1236.41 \mathrm{~cm}^{-1}$ and 908.50-455.22 $\mathrm{cm}^{-1}$. This implies lesser $\mathrm{OH}$ bonding in the mutants' EPS as these two regions are characteristic of alcohol bends.

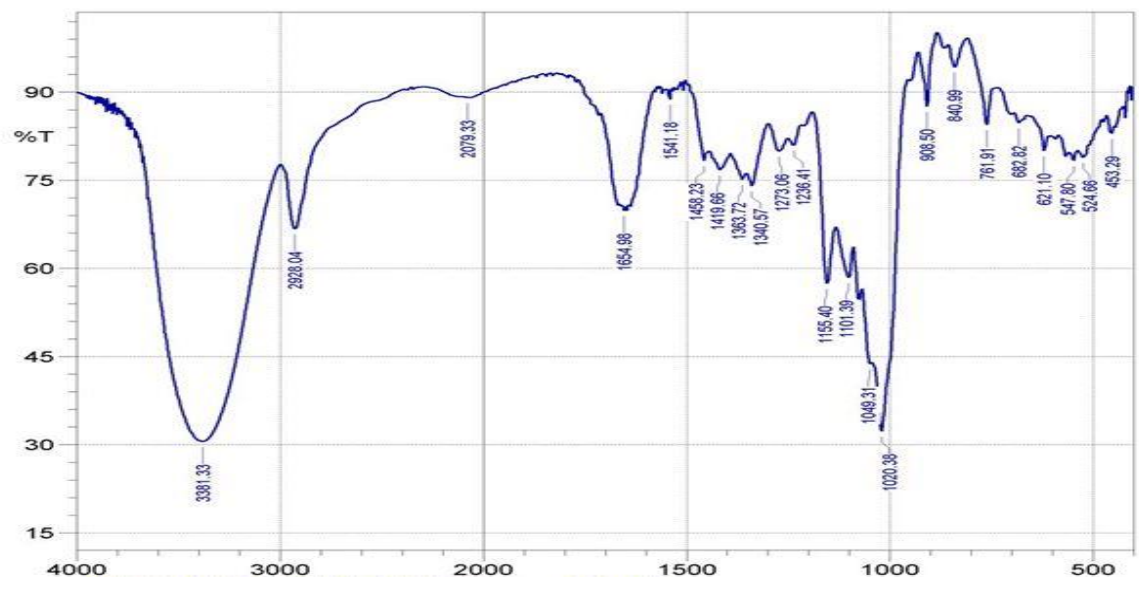

Figure 6a. FTIR Spectrum of EPS from wild type L. plantarum MK O2 


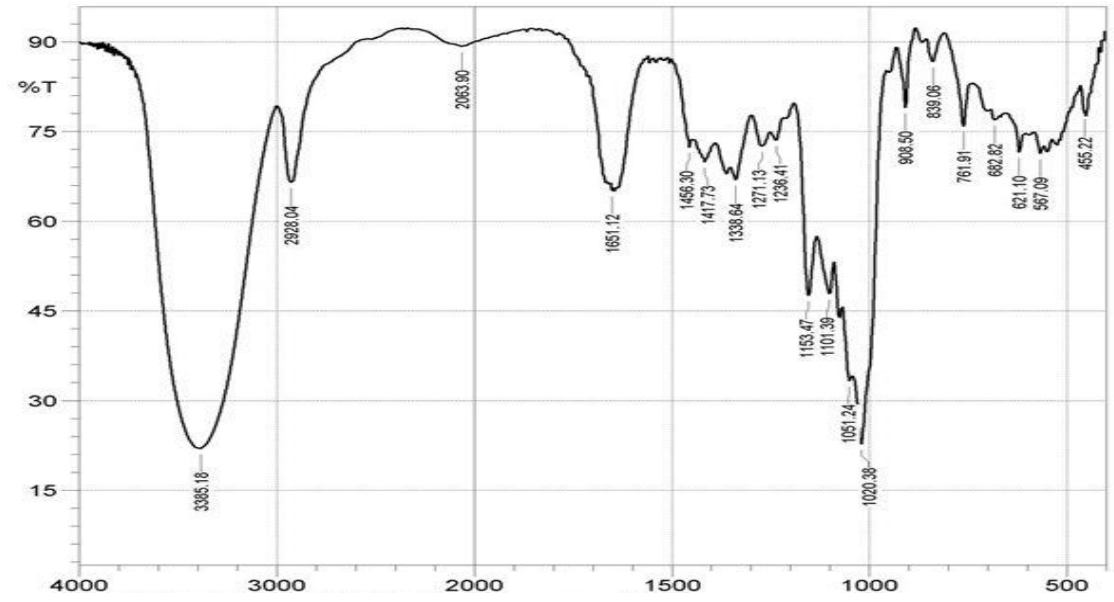

Figure 6b. FTIR Spectrum of EPS from Mutant L. plantarum Muv 11

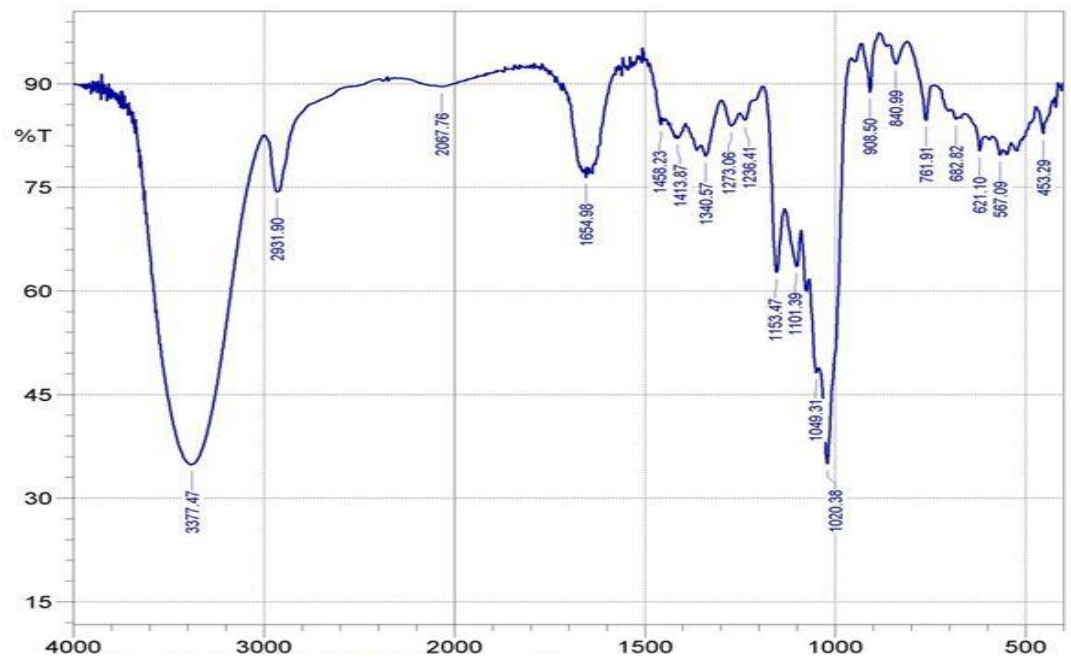

Figure 6c. $\quad$ FTIR Spectrum of EPS from Mutant L. plantarum Muv 12

Characterization of the EPS produced by the isolates using Fourier Transform Infrared Spectroscopy (FT-IR) revealed the presence of functional groups such as the hydroxyl, methyl and methylene groups as well as stretches of C$\mathrm{C}, \mathrm{C}-\mathrm{O}-\mathrm{C}$ and $\mathrm{C}-\mathrm{O}$ of alcohol groups in carbohydrates in all of the EPS. The presence of these bands in a substance indicates that the substance is a polysaccharide $(49-50)$.

In conclusion, UV radiation induces mutations in $\mathrm{LAB}$ which enables them to produce higher amounts of EPS. Immobilization studies also revealed that cell immobilization is a useful technology for the production of increased yields of EPS. Alginate-immobilized cells produced more yields of EPS than agarimmobilized cells. As the structure of EPS is related to their function, FT-IR analysis showed the presence of functional groups which confirmed the EPS as polysaccharides, thus their functions can be elucidated from the functional groups present.

\section{REFERENCES}

1. Kleerebezem, M., Van kranenburg, R., Tuinier, R., Boels, I.C., Zoon, P., Looijesteijn, E., Hugenholtz, J.and De Vos, W. M., Exopolysaccharides Produced by Lactococcus lactis: from Genetic Engineering to Improved Rheological Properties. Antonie Van Leeuwenhoek Intern J. Gene Mole Microbiol., 76: 357-365, 1999.

2. Sanchez, J.I., Martinez, B., Guillen, R., Jimenez-Diaz, R. and Rodriguez, A., Culture Conditions Determine the Balance between Two Different Exopolysaccharides Produced by Lactobacillus pentosus LPS26. Appl Environ Microbiol., 72: 7495-7502, 2006. 
3. Sutherland, I.W., Physiology and Industrial Production. In I.W. Sutherland (ed.), Biotechnology of Microbial Exopolysaccharides. Cambridge University Press, Cambridge England. 1990.

4. De Vuyst, L. and Degeest, B., Heteropolysaccharides from Lactic Acid Bacteria. FEMS Microbiol Rev., 23: 153-177, 1999.

5. Jaiswal, P., Sharma, R., Sanodiya, B.S. and Bisen, P.S., Microbial Exopolysaccharides: Natural Modulators of Dairy Products. J Appl Pharmaceu Sci., 4 (10): 105-109, 2014.

6. Sarwat, F., Qader, U., Aman, A. and Ahmed, N., Production and Characterization of a Unique Dextran from an Indigenous Leuconostoc mesenteroides CMG713. Intern J Biol Sci., 4:379-386, 2008.

7. Landersjö, C., Yang, Z., Huttunen, E. and Widmalm, G., Structural Studies of the Exopolysaccharide Produced by Lactobacillus rhamnosus strain GG (ATCC 53103). Biomacromole., 3: 880-884, 2002.

8. Górska, S., Jachymek, W. and Rybka, J., Structural and Immunochemical Studies of Neutral Exopolysaccharides Produced by Lactobacillus johnsonii 142. Carbohyd Res. 345:108114, 2010.

9. Margolles, A. and Sanchez, B., Selection of a Bifidobacterium animalis subsp. lactis Strain with a Decreased Ability to Produce Acetic Acid. Appl Environ Microbiol. 78:33383342, 2012.

10.Nakajima, H., Suzuki, Y. and Hirota, T., Cholesterol Lowering Activity of Ropy Fermented Milk. J Fd Sci., 57: 327-1329, 1992.

11.Gruter, M., Leeflang, B.R., Kuiper, J., Kamerling, J.P. and Vliegenthart, J.F.G., Structural Characterisation of the Exopolysaccharide Produced by Lactobacillus delbrueckii subspecies bulgaricus grown in Skimmed Milk. Carbohydr Res., 239: 209-226, 1993.

12.Yamamoto, Y., Nunome, T., Yamauchi, R., Kato, K. and Sone, Y., Structure of an Exocellular Polysaccharide of Lactobacillus helveticus TN-4, a Spontaneous Mutant Strain of Lactobacillus helveticus TY1-2. Carbohydr Res., 275: 319-332, 1995.

13.Lemoine, J., Chirat, F., Wie uszeski, J.M. Strecker, G., Favre, N. and Neeser, J.R., Structural Characterization of the Exocellular Polysaccharides Produced by Streptococcus thermophilus Sfi39 and Sfi12. Appl. Environ Microbiol., 63:3512-3518, 1997.
ADEBAYO-TAYO, B., et al.

14.Kojic, M., Vujcic, M., Banina, A., Cocconcelli, P., Cerning, J. and Topisirovic, L., Analysis of Exopolysaccharide Production by Lactobacillus casei CG11 Isolated from Cheese. Appl Environ Microbiol., 58: 4086-4088, 1992.

15.Low, D., Ahlgren, J.A., Horne, D., McMahon, D.J., Oberg, C.J. and Broadbent, J.R., Role of Streptococcus thermophilus MR- 1C Capsular Exopolysaccharide in Cheese Moisture Retention. Appl. Environ Microbiol., 64: 2147-2151, 1998.

16.De Vuyst, L., De Vin, F., Vaningelgem, F. and Degeest, B., Recent Developments in the Biosynthesis and Applications of Heteropolysaccharides from Lactic Acid Bacteria. Intern Diar J., 11: 687-707, 2001.

17.Sengül, N., Aslím, B. and Uçar, G., Effects of Exopolysaccharide-Producing Probiotic Strains on Experimental Colitis in Rats. Dis Col Rect., 49: 250-258, 2006.

18.German, B., Schiffrin, E., Reniero, R., Mollet, B., Pfeife, R.A. and Neeser, J.R., The Development of Functional Foods: Lessons from the Gut. Trends Biotechnol., 17: 492499, 1999.

19.Margolles, A. and Sanchez, B., Selection of a Bifidobacterium animalis subsp. lactis Strain with a Decreased Ability to Produce Acetic Acid. Appl Environ Microbiol., 78:33383342, 2012.

20.Saarela, M., Alakomi, H.L., Matto, J., Ahonen, A.M., Puhakka, A. and Tynkkynen, S., Improving the Storage Stability of Bifidobacterium breve in Low pH Fruit Juice. Inter J Fd Microbiol., 149:106-110, 2011.

21.Friedberg, E.C., Walker, G.C., Seide, W., DNA Repair and Mutagenesis. ASM Press, Washington, D.C. Pp. 28-29, 1995.

22. Chandrasekhar, D. and Houten, B.V., In Vivo Formation and Repair of Cyclobutane Pyrimidine Dimers and 6-4 Photoproducts Measured at the Gene and Nucleotide Level in Escherichia coli. Mutation Res., 450: 1940, 2000.

23.Jack, T.R., Zajic, J.E., The Immobilization of Whole Cells. Advanced Biochemical Engineering and Biotechnology, Springer Berlin 125-145, 2006.

24.Peinado, R.A., Moreno, J.J., Maestre, O. and Mauricio, J.C. Use of a Novel Immobilization Yeast System for Winemaking. Biotechnol Let., 27: 14211424, 2005.

25.Groboillot, A.F., Boadi, D.K., Poncelet, D. and Neufeld, R.J., Immobilization of Cells 
for Application in the Food Industry. Critical Rev Biotechnol., 14: 75-108, 1994.

26. Martynenko, N.N. and Gracheva, I.M., Physiological and Biochemical Characteristics of Immobilized Champagne Yeasts and their Participation in Champagnizing Processes: A Review. Appl Biochem Microbiol., 39 (5): 439-445, 2003.

27.Denkova, Z., Krastanov, A.C.P. and Murgov, I., Immobilized Lactic Acid Bacteria for Application as Dairy Starters and Prebiotic Preparation. J Gen Appl Microbiol., 50: 107114, 2004.

28. Shene, C. and Bravo, S., Whey Fermentation by Lactobacillus delbruckii subsp. bulgaricus for Exopolysaccharides Production in Continuous Culture. Enz Microb Technol., 40: 1578-1584, 2007.

29.Lacroix, C., Grattepanche, F., Doleyres, Y. and Bergmaier, D., Immobilized Cell Technologies for Dairy Industry. Applications of Cell Immobilisation Biotechnology. Springer-Verlag: Focus on Biotechnol., 8B: 295-319, 2005.

30.Sobrun, Y., Bhaw-Luximon, A., Jhurry, D. and Puchooa, D., Isolation of Lactic Acid Bacteria from Sugar Cane Juice and Production of Lactic Acid from Selected Improved Strains. Adv Biosci Biotechnol., 3: 398-407, 2012.

31.Dubois, M., Gilles, K.A., Hamilton, J.K., Rebers, P.A. and Smith, F., Colorimetric Method for Determination of Sugars and Related Substances. Analyt Chemist., 28: 350-356, 1956.

32.Van Den Berg, D.J.C., Smits, A., Pot, B., Ledeboer, A.M., Kersters, K., Verbakel, J.M.A and Verrips, C.T., Isolation, Screening and Identification of Lactic Acid Bacteria from Traditional Food Fermentation Process and Culture Collections. Fd Biotechnol., 7:189-205, 1993.

33.Ludbrook, K.A., Russel, C.M. and Greig, R.I. Exopolysaccharide Production from Lactic Acid Bacteria Isolated from Fermented Food. J Fd Sci., 62: 597-600, 1997.

34.De, S., Kaur, G., Roy, A., Dogra, G.., Kaushik, R., Yadav, P., Singh, R., Datta, T.K. and Goswami, S.L. A Simple Method for the Efficient Isolation of Genomic DNA from Lactobacilli Isolated from Traditional Indian Fermented Milk (dahi). Ind $J$ Microbiol., 50(4): 412-418, 2011.

35.Pasha, Y.S., Ali, M.N., Tabassum, H. and Mohammed, M.K., Comparative Studies on Production of Glutamic Acid using Wild
ADEBAYO-TAYO, B., et al.

Type, Mutants, Immobilized Cells and Immobilized Mutants of Corynebacterium glutamicum. Intern J Engineer Sci Technol., 3 (5): 3941-3949, 2011.

36.Manohar, S. and Karegoudar, T.B., Degradation of Naphthalene by Cells of Pseudomonas sp. Strain NGK1 Immobilized in Alginate, Agar and Polyacrylamide. Appl Microbiol Biotechnol. 49: 785-792, 1998.

37.Cerning, J., Production of Exopolysaccharides by Lactic Acid Bacteria and Dairy Propionibacteria. Lait, 75: 463472, 1995.

38.Karigar, C., Mahesh, A., Nagenahalli, M. and Jin Yun, D., Phenol Degradation by Immobilized Cells of Arthrobacter citreus. Biodegrad., 17: 47-55, 2006.

39. Coates, J., Interpretation of Infrared Spectra, A Practical Approach. In: Meyers, R.A. (Ed.) Encyclopedia of Analytical Chemistry. John Wiley and Sons, Chichester pp. 1081510837, 2000.

40.Tallon, R., Bressollier, P. and Urdaci, M.C., Isolation and Characterization of Two Exopolysaccharides Produced by Lactobaciilus plantarum EP56. Res Microbiol., 154: 705-712, 2003.

41.Francois, Z., Ahmed, N., Fe'licite, M., Elsoda, M., Effect of Ropy and Capsular Exopolysaccharides Producing Strain of Lactobacillus plantarum 162RM on Characteristics and Functionality of Fermented Milk and Soft Karish type Cheese. Afri J Biotechnol., 3: 512-518, 2004.

42.Remus, D.M., van Kranenburg, R., van Swam, H., Taverne, N., Bongers, R.S., Wels, M., Wells, J.M., Bron, P.A. and Kleerebezem, M., Impact of 4 Lactobacillus plantarum Capsular Polysaccharide Clusters on Surface Glycan Composition and Host Cell Signaling. Microbial Cell Fact., 11: 149, 2012.

43.Pasha, Y.S., Ali, M.N., Tabassum, H. and Mohammed, M.K., Comparative Studies on Production of Glutamic Acid using Wild Type, Mutants, Immobilized Cells and Immobilized Mutants of Corynebacterium glutamicum. Intern J Engineer Sci Technol., 3 (5): 3941-3949, 2011.

44.Bergmaier, D., Champagene, C.P. and Laeroix, C., Exopolysaccharide Production during Batch Cultures with Free and Immobilized Lactobacillus Rhamnosus RW9595M. J Appl Microbiol., 95: 1049-1057, 2003. 
45.Bergmaier, D., Champagene, C.P. and Laeroix, C., Growth and ExopolysaccharidesProduction during Free and Immobilized Cell Chemostat Culture of Lactobacillus Rhamnosus RW-9595M. J Appl Microbiol., 98: 272-284, 2005.

46.El-Gizawy, S.A., Barakat, O.S., Sharaf, O.M., EL-Shafei, K., Fathy, F.A. and ELSayed, H.S., Effect of Growth Conditions on the Production of Exopolysaccharides by Microencapsulated Lactobacillus bulgaricus and Use it to Improve Quality of Kareish Cheese. J Appl Sci Res., 9 (2): 1097-1109, 2013.

47.Ismail, B. and Nampoothiri, K.M., Exopolysaccharide Production and Prevention of Syneresis in Starch using
ADEBAYO-TAYO, B., et al.

Encapsulated Probiotic Lactobacillus plantarum. Fd Technol Biotechnol., 48(4): 484-489, 2010

48. Coates, J., Interpretation of Infrared Spectra, A Practical Approach. In: Meyers, R.A. (Ed.) Encyclopedia of Analytical Chemistry. John Wiley and Sons, Chichester, pp. 1081510837, 2000.

49.Cho, J., Amy, G., Pellegrino, J. and Yoon, Y., Characterization of Clean and Natural Organic Matter (NOM) Fouled NF and UF Membranes and Foulants Characterization. Desalination 118, 101-108, 1998.

50.Nataraj, S., Schomacker, R., Kraume, M., Mishra, M.I. and Drews, A., Analyses of Polysaccharide Fouling Mechanisms during Crossflow Membrane Filtration. J Membrane Sci., 308: 152-161, 2008. 
